\title{
A ICONOGRAFIA EM REVISÃO
}

\author{
La iconografía en revisión
}

The iconography under review

Altamir Moreira $^{1}$

\begin{abstract}
Resumo
Este texto discute a atualidade da abordagem iconográfica. A partir da definição de conceitos baseada em Erwin Panofsky, relaciona alguns desenvolvimentos e críticas a respeito desse campo de conhecimentos. Aponta possibilidades de aplicação da iconografia no estudo da arte contemporânea, a partir de duas pesquisas teóricas orientadas pelo autor no Programa de Pós-Graduação em Artes Visuais da UFSM.
\end{abstract}

Palavras-chave: Iconografia; Iconologia; Erwin Panofsky

\section{Resumen}

Este texto discute la actualidad del enfoque iconográfico. A partir de la definición de conceptos basada en Erwin Panofsky, relaciona algunos desarrollos y críticas acerca de ese campo de conocimientos. Aponta posibilidades de aplicación de la iconografía en el estudio del arte contemporáneo a partir de dos investigaciones teóricas orientadas por los autores en el Programa de Postgrado en Artes Visuales de la UFSM.

Palabras-clave: Iconografía; Iconología; Erwin Panofsky

\begin{abstract}
This text discusses the actuality of the iconographic approach. From the concept definition based on Erwin Panofsky, it relates some developments and critiques about this field of knowledge. It points out possibilities of application of iconography in the study of contemporary art based on two theoretical researches guided by the authors in the Postgraduate Program in Visual Arts of UFSM.
\end{abstract}

Keywords: Iconography; Iconology; Erwin Panofsky

\section{Introdução}

1 - Altamir Moreira (1972): Doutor em Artes Visuais pela UFRGS. Pesquisador na área de iconologia da pintura mural religiosa. Atualmente é Professor Adjunto do Departamento de Artes Visuais da UFSM, e Professor Colaborador do Programa de Pós-Graduação em Artes Visuais daquela Instituição - e-mail: althamir@gmail.com 
Este estudo surge a partir de um questionamento recorrente entre estudantes de artes: a iconografia não seria uma abordagem teórica ultrapassada para o estudo de obras contemporâneas? Como pode ser avaliado ao longo do texto, meu posicionamento é que a abordagem iconográfica, em suas diversas variantes históricas, ainda pode ser produtiva quando aplicada a obras recentes elaboradas com marcante apelo simbólico e recurso à figuração. A partir de um breve resumo sobre o desenvolvimento histórico dessa área de conhecimento, pretende auxiliar no esclarecimento dessa questão, comum ao acadêmico que deseja realizar seu primeiro projeto na área de iconografia. Para tanto, o resumo teórico inicial é complementado com um relato sobre as pesquisas teóricas que realizei em minha trajetória acadêmica, e com outras que orientei durante a docência no Programa de Pós-Graduação em Artes Visuais da UFSM.

\section{Iconografia ou iconologia?: controvérsias e definições}

Segundo a linha de pensamento defendida por Erwin Panofsky (1892 - 1968), em textos tardios, iconografia é a denominação dada ao estudo dos significados convencionais das imagens, e iconologia refere-se à interpretação que vai além dos dados visuais e sintetiza o significado cultural mais profundo da imagem. Porém, quando se considera o campo iconográfico em abrangência maior que a linha panofskyana, pode-se dizer que não há um consenso geral sobre o uso apropriado e a definição dos termos iconografia e iconologia. Tudo depende do quadro teórico tomado como referência e, em geral, ambas definições possuem significados que, parcialmente, se sobrepõem.

Em 1939, Panofsky denominava Iconografia o ramo da história da arte que trata do significado das obras de arte. E a prática interpretativa aplicada a esse campo era subdividida em fases de: descrição pré-iconográfica, análise iconográfica, e interpretação iconográfica, em sentido mais profundo (PANOFSKY,1995, p. 26). Ao revisar o texto para a versão publicada em 1955, Panofsky renomeia a terceira fase do método. No lugar de interpretação iconográfica ele inclui a interpretação iconológica, fundamentando a seguir que o sufixo "grafia", oriundo do verbo grego graphein, implica em escrever, derivando disso a função descritiva da iconografia. Por isso, propõe reviver o antigo termo iconologia, que possui o sufixo "logia", do grego logos: "pensamento, razão" para definir a fase interpretativa do método (PANOFSKY, 2017, p. 53). Nesse ponto, pode-se dizer que definição de Panofsky é etimologicamente justificada. Porém, essa atualização do termo não é coerente com o antigo significado de iconologia, presente no antigo tratado de Cesare Ripa (c.1560 - 1622)², em que o vocábulo refere-se à atividade descritiva de alegorias.

No mesmo ano da atualização conceitual procedida por Panofsky, o historiador francês Louis Réau (1881 - 1961) publica o primeiro volume de seu compêndio dedicado à iconografia da arte cristã. E, na introdução dessa obra, ele também questiona se a denominação iconologia não era mais adequada que iconografia. Pois, embora reconheça que a palavra iconologia tenha sido historicamente relacionada à ciência das alegorias, ela realmente significa "ciência das imagens". E, como tal, seria apropriada para descrever a análise iconográfica. "[...] pois, o iconógrafo não se limita a descrever as obras. Sua ambição vai mais além e aspira classificá-las e interpretá-las"(RÉAU, 2000, p. 13). Talvez, esse tipo de questionamento, ou indefinição conceitual, explique porque as disciplinas dedicadas a essa área continuem sendo descritas por termos justapostos: iconografia e iconologia.

Mas, pode ser que após conhecermos a problemática histórica relacionada à definição dos termos dessa abordagem metodológica, uma dúvida recorrente ainda venha nos inquietar: como denominar adequadamente um estudo realizado dentro da abordagem sugerida por Panofsky? Para tanto, é útil reconhecermos que é inteiramente possível realizar um estudo iconográfico consistente, sem aceder ao nível interpretativo das sínteses culturais. Mas, o mesmo trabalho não é possível de ser levado a termo diretamente no campo da iconologia, pois tal intento não é viável sem o embasamento anterior dos níveis descritivos. Portanto, a iconologia é um nível iconográfico e não um campo independente.

Desse modo, segundo nosso entendimento, é correto denominarmos iconográficas as abordagem desenvolvidas com base na teoria de Panofsky, quer sejam puramente descritivas, ou acentuadamente interpretativas, pois ainda integram o campo expandido original da iconografia. Assim como podemos descrever como iconológicas aquelas abordagens que, adequadamente, se caracterizam pelas ênfases interpretativas. Porém, segundo este mesmo entendimento, continua sendo inadequado classificarmos como iconológicas as pesquisa puramente descritivas, ou decodificadoras de significados convencionais.

\section{Iconografia: continuidades e desafios}

2 - O termo iconologia retomado por Panofsky foi usado por Cesare Ripa no século XVI para denominar sua compilação de alegorias visuais, construídas a partir de pinturas e textos antigos. Iconologia, portanto, definia tanto o processo de codificação quanto a atividade de descrição de significados das imagens. Estas, por sua vez, eram elaboradas para transmitir conceitos, geralmente, difíceis de se descrever por meios visuais, tais como: amor virtuoso, fama, ou hospitalidade. Para um entendimento fundamentado em Panofsky, a antiga iconologia, baseada na descrição, seria mais adequadamente classificada como iconografia. 
A iconografia conheceu seu auge na segunda metade do século XX, graças ao reconhecimento obtido pelos trabalhos de Erwin Panofsky e, em parte, devido às pesquisas de teóricos vinculados à chamada Escola de Warburg ou à iconografia de tradição francesa. Mas, ainda no final do século passado, com a progressiva ascensão de pensadores identificados com abordagens pós-estruturalistas, e de revisões críticas da iconografia histórica, houve uma diminuição do interesse por essa área de pesquisa teórica em artes. Embora seu potencial na prática analítica de imagens não fosse inteiramente negado. Diante disso, é adequado retomarmos o questionamento proposto pelo iconólogo espanhol Rafael García Mahíques (2008, p. 411 - 470) no primeiro volume de seu estudo sobre iconografia e iconologia: Após a morte de Ernest H. Gombrich, em 2001, a tradição de estudos iconológicos estaria concluída? Indagação a qual ele responde negativamente, destacando que contínuas revisões desse tipo de abordagem vêm ocorrendo desde os anos 60, em obras de historiadores como Michel Podro (1931 - 2008), Michel Baxandall (1933 2008) e Svetlana Alpers. Ainda que reconheça que estes trabalhos estariam cada vez mais imersos em um campo de reflexão mais amplo chamado de Estudos Visuais, ou ainda Cultura Visual.

Seus principais promotores buscam defini-lo como estudo visual da imagem, tendo em conta esta em uma limite global além do estético, ou considerando não somente aqueles objetos que tem sido designados como de interesse estético. Chegaram a defender, inclusive, a constituir-se enquanto alternativa à história da arte como disciplina. (MAHÍQUES, 2008, p. 412)

Michel Baxandall, citado por Mahíques entre os colaboradores do processo de revisão da iconografia, trabalhou no Instituto Warburg a partir de 1958, e nos três anos seguintes pesquisou sob orientação de Gombrich ${ }^{3}$. Foi professor de Estudos Renascentistas nessa instituição a partir de 1965, e tornou-se conhecido pelas contribuições à história social da arte, sobretudo pelo estudo sobre Pintura e experiência na pintura do século XV (1972) ${ }^{4}$. Obra na qual aborda a capacidade visual desenvolvida por intermédio de experiências cotidianas e sua influência no estilo da pintura daquela época. Mas, é na obra Padrões de intenção $(1985)^{5}$ que ficam mais evidentes as influências da tradição iconográfica. Sobretudo, a contribuição da "metodologia iconológica de Gombrich: o problema da intencionalidade do artista como modo de conhecer e interpretar a imagem artística" (MAHÍQUES, 2008, p. 427). Evidente quando Baxandall propõe, e exemplifica, sua abordagem da imagem artística pela análise de obras do renascimento, barroco, e período moderno. Situações em que destaca evidências históricas, além de fatores deduzidos da cultura, trajetória do pensamento, e intenções racionais dos artistas durante a criação da obras.

Svetlana Alpers também estudou sob orientação de Gombrich, e é considerada responsável por alguns dos principais desenvolvimentos críticos da iconologia no final do século XX, embora ela, provavelmente, prefira não ser limitada a nenhuma linha de pensamento específico (MAHÍQUES, 2008, p. 435). Sua obra mais conhecida é A arte de descrever (1983) dedicada à arte do século XVIII'. Estudo no qual propõe superar as limitações da análise iconológica que Panofsky dedicou à arte barroca holandesa. Sobretudo, em temas onde a narrativa não é um aspecto essencial, mas, sim, a questão descritiva. "O que Panofsky diz de van Eyck é perfeitamente exato. Mas os 'padrões ordinários' que ele invoca nada mais são que as expectativas da ação narrativa criadas pela arte italiana" (ALPERS, 1999, p. 30). Alpers propõe preencher uma lacuna do acesso ao significado primário da imagem com a inclusão do problema da representação.

Conforme observa Mahíques, historiadores como Baxandall e Alpers dificilmente admitiriam ser classificados como iconólogos, porém sobram razões para considerá-los como tais. Entre as características que se destacam no trabalho de ambos, está o renovado interesse pelos aspectos formais das imagens. Embora Panofsky entendesse que as questões técnicas e formais das obras devessem ser consideradas na interpretação iconológica, “Baxandall e Alpers, não obstante, parecem ser mais conscientes, quem sabe, da impossibilidade da separação entre forma e conteúdo e tendem a estudar ambas coisas conjuntamente [...]" (MAHÍQUES, 2008, p. 441)7. Baxandall tende a enfatizar questões essencialmente pictóricas, resultantes dos procedimentos e experiências visuais do pintor, deixando de lado a interpretação de simbolismos ocultos, alcançando com isso uma iconografia minimalista.

Para Baxandall, assim como Alpers, o objeto de estudo não é tanto a obra artística mas sim a visualidade, entendida como

3 - Na época, Baxandall realizava pesquisa para uma tese de doutorado sobre Restrições e comportamentos na Renascença, trabalho que ele jamais concluiu.

4 - Ver a versão portuguesa: BAXANDALL, Michel. O olhar renascente: pintura e experiência social da Itália na Renascença. Rio de Janeiro: Paz e Terra, 1991.

5 - Disponível em versão portuguesa: BAXANDALL, Michel. Padrões de intenção: a explicação histórica dos quadros. São Paulo: Companhia das Letras, 2006.

6 - Disponível em versão portuguesa. Ver: ALPERS, Svetlana. A arte de descrever. São Paulo: Edusp, 1999.

7 - No texto original: "Baxandall y Alpers, no obstante, son más conscientes quizás de la impossibilidad de diseccionar forma y contenido y tienden a estudiar ambas cosas conjuntamente [...]". 
conjunto de características pictóricas e iconográficas primárias das imagens. Uma visualidade derivada da Cultura Visual que permeia a mentalidade da sociedade contemporânea às obras estudadas (MAHÍQUES, 2008, p. 442). Mas, o contínuo questionamento crítico do método iconológico, mesmo com recorrência a algumas de suas abordagens primárias, seriam indícios da superação histórica dessa abordagem? Ou ainda, da dissolução desta em um campo mais amplo como o da Cultura Visual, ou dos Estudos Culturais? A questão permanece em aberto para a discussão.

\section{Iconografia e crítica pós-estruturalista}

Daniel Arasse (1944 - 2003), aluno de André Chastel (1912 - 1990) e de Louis Marin (1931 - 1992), também merece ser considerado na atualização da abordagem iconográfica, sobretudo por meio do estudo dedicado às funções do detalhe na história da pintura (ARASSE, 1886). Uma tentativa de se extrair consequências práticas de uma tradicional expressão alemã, frequentemente repetida por Aby Warburg (1866 - 1929): “Der Liebe Gott stecke im Detail” (Deus está no detalhe!). Na obra O Detalhe (1996), ele diferencia as funções do detalhe: o pictórico que não tem finalidade representativa além da própria matéria, e o detalhe icônico que imita o objeto. Um exemplo jocoso da função do detalhe icônico é resgatado de uma observação do historiador Paul Barolsky, sobre uma pintura renascentista dos Esponsais da Virgem (1523), de Rosso Fiorentino (1495 -1540). Na ambientação do casamento de São José e a Virgem Maria, o pintor introduz um monge dominicano com os dedos polegar e indicador apontados para a parte central da cena, projetando-se: "defronte os quadris de São José, indicando sutilmente (ou talvez pouco sutilmente) a excitação sexual do noivo" (ARASSE, 1996, p. 328). Atitude atribuída ao espírito bem humorado de Rosso, e do Cardeal Ginori, patrocinador da pintura.

Figura 1- Rosso Fiorentino. Os esponsais da Virgem, 1423. Óleo sobre Madeira. Igreja de San Lorenzo Florença

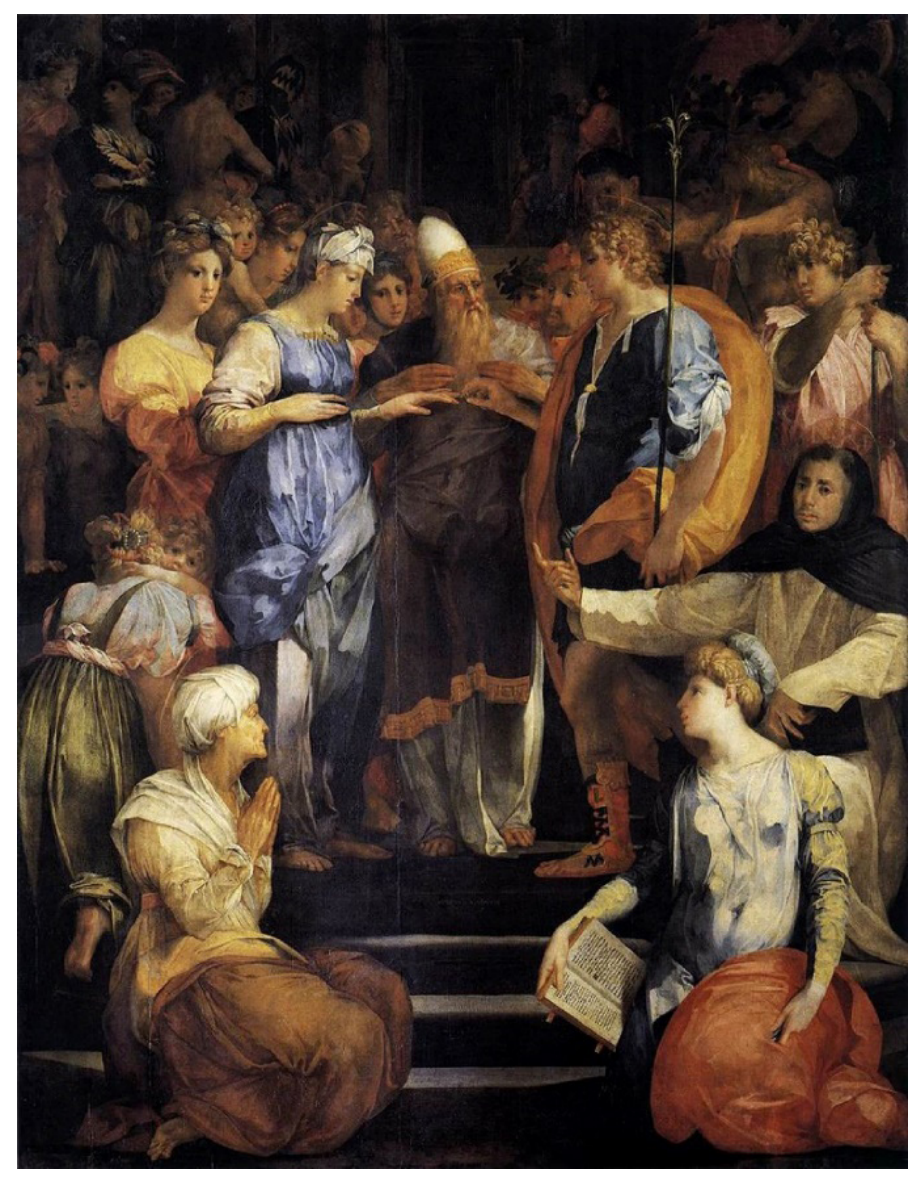

Fonte: (WEB ART GALLERY, 2018) 
Mas, Arasse também adverte o pesquisador que almeja construir uma interpretação iconográfica com a identificação precisa dos motivos representados pode, por vezes, ser enganando pelo desejo desmedido de descobrir significados. Caso exemplificado pela análise que Sigmund Freud dedicou ao quadro de Santa Ana, a Virgem e o Menino Jesus (DA VINCI, 2018), no qual a imagem de um abutre somente se tornou possível pelos excessos do desejo de interpretar . $^{8}$

Louis Marin (1931 - 1992), reconhecido como um filósofo pós-estruturalista, também reservou parte de suas reflexões para o campo da iconografia. No artigo Panofsky e Poussin na Arcádia, ele retoma de modo crítico o estudo que o historiador alemão dedicou à pintura Os pastores na Arcádia de Possinn ${ }^{9}$, e ao detalhe da inscrição latina Et in Arcádia Ego. Marin analisa o modo como Panofsky aplicou o próprio método no artigo final e duas versões anteriores do artigo sobre Poussin. Conclui que Panofsky opta por determinada tradução da frase et in Arcádia ego. Interpretada como: também vivi na Arcádia, e não desenvolve as versões alternativas, tais como: eu, a morte, também estive na Arcádia, ou mesmo na morte, pode existir a Arcádia.(MARIN, 2000, p. 97 - 119). Portanto, ele considera que nesse caso a investigação filológica insuficiente teria comprometido a interpretação do significado da imagem.

Georges Didi-Huberman, ex-orientando de Louis Marin, é outro historiador da arte inserido de tendência pós-estruturalista que também realizou uma revisão crítica do método de Panofsky. No livro Diante da imagem (1990), ele busca fundamentar uma crítica à questão da intuição sintética, que Panofsky considera necessária no terceiro nível da análise da imagem. Didi-Huberman entende que a síntese interpretativa conduz a história da arte a uma limitação desnecessária dos significados possíveis de uma imagem ${ }^{10}$.

Em contraponto à síntese de Panofsky, Didi-Huberman propõe o conceito de pano visual, que privilegia a análise dos sintomas por meio de análise e discussão de indícios visuais cuja ausência de identificação definitiva deve ser considerada como problema metodológico. Apesar de contrapor-se ao método de iconográfico de Panofsky, ele ressalva que tal crítica não é extensível ao antecessor desse tipo de abordagem, uma vez que Aby Warburg não pensava da mesma forma (DIDI-HUBERMAN, 1990, p. 154). De modo que o historiador francês tem se dedicado, com frequência, ao aprofundamento de alguns conceitos relacionados ao estudo de imagens, como pathos, sintoma e fantasma, a partir dos estudos históricos e iconográficos de Warburg.

Com isso, concluo o resumo sobre algumas das possibilidades teóricas que devem ser consideradas pelo pesquisador iniciante no campo da iconografia, a respeito das limitações destacadas e aportes sugeridos para a renovação dessa área. A seguir, incluo um breve relato pessoal sobre minha experiência neste campo teórico, com objetivo de exemplificar algumas possibilidades de aplicação da iconografia ao campo da arte contemporânea.

\section{Minha iniciação à iconografia}

Meu contato com a área de iconografia se deu durante meus estudos de pós-graduação na UFRGS, período em que eu desenvolvia uma dissertação sobre a pintura mural religiosa em igrejas da Quarta Colônia, região central do Rio Grande do Sul (MOREIRA, 2001). Inicialmente estudei a abordagem iconográfica tradicional de Panofsky por indicação de meu orientador Dr. José Augusto Costa Avancini. Logo, mais tarde, quando cursava a disciplina de Iconografia e Iconologia com o professor Dr. Armindo Trevisan, tomei conhecimento sobre alguns historiadores franceses que também pesquisaram essa área. Armindo já era conhecido regionalmente por um trabalho iconográfico realizado sobre a escultura missioneira do Rio Grande do Sul (TREVISAN, 1978). E, nessa época, pesquisava dados iconográficos que resultaram na obra O Rosto de Cristo, estudo em que analisou a transmissão cultural de variantes históricas da imagem de Jesus, da arte paleocristã às reconstruções históricas contemporâneas (TREVISAN, 2003). Ele recomendou-me a leitura da Iconografia da Arte Cristã de Louis Réau (1881 - 1961), disponível, no idioma original, na biblioteca central da universidade em uma série de cinco pesados volumes. Obra que se mostrou de inestimável valor para a identificação de vários temas religiosos com os quais me deparei no desenvolvimento inicial de minha pesquisa.

Ainda durante os estudos na UFRGS, participei junto a alguns pós-graduandos de um grupo de discussões acadêmicas, de caráter informal, denominado Núcleo de Estudos em História da Arte e Humanismo ${ }^{11}$, com ênfase em iconografia e história da arte. Coordenado por meu orientador, José Augusto Avancini, e por Francisco Marshall ${ }^{12}$, na época recém retornado

8 - Uma versão portuguesa do texto, alvo da crítica de Arasse, foi publicada em: FREUD, Sigmund. Leonardo da Vinci e uma lembrança de Sua Infância. In: Leonardo da Vinci e uma lembrança de Sua Infância - O Moisés de Michelangelo. Rio de Janeiro: Imago, 1997.

9 - O artigo de Panofsky entitulado: Et in Arcadia Ego: Poussin e a tradição elegíaca, foi publicado no livro Meaning in the Visual Arts (1955). Acessível na versão portuguesa: PANOFSKY, Erwin. Significado nas artes visuais. São Paulo: Perspectiva, 2017, p. 377 - 409.

10 Abordo com maior ênfase a crítica de Didi-Huberman exposta em Devant L'Image no artigo: MOREIRA, Altamir. Didi-Huberman: Reflexões sobre a Síntese e o Sintoma na Teoria da Arte, 2010.

11 - Segundo o meu caderno pessoal de notas, na época o grupo era coordenado pelo Dr. José Augusto Costa Avancini, e Dr. Francisco Marshall, e composto, basicamente, por orientandos desses dois professores. Durante a breve existência contou com integrantes oriundos da pós-graduação em história e orientando da pós-graduação em artes visuais. Foi um grupo não registrado na instituição, que durou de outubro a de 1999 a junho de 2001 , motivado pelo interesse pessoal dos integrantes em aprofundar o estudo do legado da escola de Warburg e de historiadores ligados à história cultural. 
de seus estudos de pós-doutorado na Universidade de Princeton, um dos principais centros de estudos iconográficos. As discussões geralmente eram dirigidas por um dos integrantes do grupo a partir de textos históricos de historiadores ou divulgadores das teorias da escola de Warburg, tais como: E. H. Gombrich (1909 - 2001) , Edgar Wind (1900 -1971), Robert Klein (1918 - 1967), Carlo Ginzburg e do diplomata brasileiro José Guilherme Merquior (1941 -1991) ${ }^{13}$. Era um grupo que estimulava a livre discussão sobre as teorias históricas, no qual não estávamos submetidos a avaliações por desempenho, e cuja continuidade era assegurada apenas pelos interesses particulares de aprofundar o conhecimento sobre os fundamentos da história da arte.

A abordagem iconográfica está na base dos trabalhos que desenvolvi durante a pós-graduação. A dissertação sobre a iconografia das pinturas murais de Angelo Lazzarini, nas igreja da Quarta Colônia (MOREIRA, 2001), é em grande parte embasada na abordagem de Panofsky, e nos dados iconográficos fornecidos por Louis Réau. Este tipo de enquadramento metodológico também se faz presente em artigos posteriores sobre a obra de Angelo Lazzarini (1899 - 1964) e de Aldo Locatelli (1915 - 1962) (MOREIRA, 2002,2005). Já a tese sobre o tema da morte e do além na pintura mural religiosa da região central do Rio Grande do Sul (MOREIRA, 2006), por sua vez, é devedora, em maior grau, da atualização do conceito de Aby Warburg sobre a questão das formas que transmitem sentimento (pathosformell), aliada a uma abordagem formalista de cunho mais psicológico presente nos primeiros estudos de Heinrich Wölfflin (1864 - 1945). A influência de Warburg também é destacada no artigo sobre a expressão de sentimentos na pintura de Aldo Locatelli sobre a morte de São Luiz Gonzaga (MOREIRA, 2004).

\section{Orientando pesquisas no PPGART}

Em relação ao meu trabalho como orientador na linha de pesquisa de Arte e Cultura, no curso de Pós-Graduação em Artes Visuais da UFSM, posso destacar dois trabalhos que envolvem as possibilidades da abordagem do campo da iconografia aplicado à arte contemporânea, exemplificados pelas dissertações das pesquisadoras Ana Paula Witeck e Gicelda de Lucca Flores.

Ana Paula Gomes Witeck desenvolveu um estudo iconográfico sobre o tema das Vanitas presente em obras de arte contemporânea (WITECK, 2012). Ela questiona em que medida o termo "Vanitas Contemporâneas", utilizado para descrever obras que incorporam motivos iconográficos tradicionais como, por exemplo, imagens de flores e crânios humanos, é adequado para definir a produção visual de décadas recentes, realizadas em contexto amplamente laico. Tendo como base a análise iconológica de Panofsky, ela desenvolve uma síntese histórica em que conclui que estas obras mais recentes não configuram uma simples continuidade do tema religioso presente nas vanitas do período barroco, mas recriações que apresentam grande distância formal em relação aos precedentes históricos, embora preservem a ideia de questionamento das vaidades humanas diante da preocupação com a efemeridade ainda presente da vida contemporânea. Esse tipo de abordagem, voltada ao esclarecimento de definições históricas de vanitas em sua relação com a arte contemporânea, também é retomada em artigos posteriores, como o que ela dedica às obras dos artistas Nigel Cooke e Luis Zerbini (WITECK, 2012b); e um estudo em que aborda obras exemplares de três exposições específicas: Vanitas: meditations on life and death in contemporary art, Estados Unidos, 2000; C'est la Vie! Vanités de Caravage à Damien Hirst, França, 2010, e Still life/Natureza-Morta, Brasil, 2004 - 2005. (WITECK, 2011).

Gicelda de Lucca Flores utilizou a abordagem iconográfica para analisar motivos recorrentes na obra de uma artista contemporânea. Na dissertação intitulada Karin Lambrecht: questões sobre uma visualidade existencial (FLORES, 2015). Gicelda seleciona algumas formas simbólicas representadas pelo motivo da cruz, pelas palavras e vestígios pictóricos. Conforme Gicelda, a investigação dessa simbologia permitiu que fossem introduzidas novas indagações fatores à pesquisa, "com questões voltadas ao existencialismo, tanto cristão quanto ateu" (FLORES, 2015a, p. 145). Também foram percebidos rituais e temas antigos, a exemplo do carneiro sacrificial que inter-relaciona temáticas da morte, vida e religiosidade. A partir dos elementos simbólicos escolhidos, da pesquisa iconográfica do acervo de obras anteriores, de informações documentais do contexto, e por meio de entrevistas com a artistas, ela vislumbra e destaca uma das possíveis questões norteadoras da poética dessa artista: a preocupação com a efemeridade do corpo e os questionamentos sobre a vida. Este estudo também é retomado de modo resumido no artigo sobre a visualidade da obra de Karin Lambrecht, publicado nos anais da ANPAP (FLORES, 2015b).

\section{Continuidades possíveis no campo iconográfico}

Para que haja desenvolvimento de estudos na área de iconografia, é necessário que existam pesquisadores que deem continuidade ao questionamento recorrente da função simbólica da imagem na arte, seja de períodos pretéritos ou de

12 Conforme dados da Plataforma Lattes, Francisco Marshall ainda desenvolve estudos iconográficos coordenando uma linha de pesquisa denominada Paganismo em Cristianismo: diálogos e conflitos iconográficos. In: <http://buscatextual.cnpq.br/buscatextual/visualizacv.do?id=K4763606A0>.

13 Merquior foi um eficiente compilador das ideias de Edgar Wind. Conferir MERQUIOR, José Guilherme. Formalismo e Tradição Moderna: o problema da arte na crise da cultura. São Paulo: USP, 1974. 
produções contemporâneas. Para tanto, não basta a simples continuidade e retomada dos métodos tradicionais, é preciso considerar os desenvolvimentos paralelos, as críticas, e as propostas alternativas que possam ser incorporadas com proveito na atualização das abordagens iconográficas.

Portanto, é proveitoso considerar, na atualidade, que a permanência e o desenvolvimento do campo de estudos em iconografia devem-se, em grande parte, não somente à solidez da fundamentação teórica dos precursores do método, mas, também, a sucessivas contribuições de historiadores da arte de campos de estudos da psicologia da percepção, cultura visual e micro-história, e, porque não, das críticas metodológicas advindas de historiadores com perspectivas pós-estruturalistas.

\section{Referências}

ALPERS, Svetlana. A arte de descrever. São Paulo: Edusp, 1999.

ARASSE, Daniel. Le Détail: pour une histoire rapproché de la peinture. Paris: Flammarion, 1996.

BAXANDALL, Michel. O olhar renascente: pintura e experiência social da Itália na Renascença. Rio de Janeiro: Paz e Terra, 1991.

BAXANDALL, Michel. Padrões de intenção: a explicação histórica dos quadros. São Paulo: Companhia das Letras, 2006.

DA VINCl, Leonardo da. Sainte Anne, la Vierge et I' Enfant jouant avec un agneau, dite La Sainte Anne. Crédito da Imagem: Museu du Louvre/ René-Gabriel Ojéda. Disponível em: <https://www.louvre.fr/en/oeuvre-notices/virginand-child-saint-anne>. Acesso em: 18 fev. 2018.

DIDI-HUBERMAN, Georges. Devant L'Image: question posée aux fins d'une histoire de l'art. Paris: De Minuit, 1990.

FLORES, Gicelda de Lucca; MOREIRA, Altamir. A visualidade existencial na obra de Karin Lambrecht. Anais do 24 Encontro da ANPAP, 2015a, p. 805-823.

FLORES, Gicelda de Lucca. Karin Lambrecht: questões sobre uma visualidade existencial. Santa Maria: PPGART - UFSM. Dissertação de Mestrado, 2015 b.

FREUD, Sigmund. Leonardo da Vinci e uma lembrança de Sua Infância - O Moisés de Michelangelo. Rio de Janeiro: Imago, 1997.

MAHÍQUES, Rafael García. Iconografía e iconología: la historia de arte como historia cultural. Volumen I. Madrid: Ecuentro, 2008.

MARIN, Louis. Sublime Poussin. São Paulo: EDUSP, 2000.

MERQUIOR, José Guilherme. Formalismo e tradição Moderna: o problema da arte na crise da cultura. São Paulo: USP, 1974.

MOREIRA, Altamir.A Pintura mural religiosa, de Angelo Lazzarini, nas Igrejas da Quarta Colônia. Porto Alegre: UFRGS, 2001 (Dissertação de mestrado).

MOREIRA, Altamir. Arte mural religiosa: questões sobre as obras de Angelo Lazzarini, e de Aldo Locatelli, nas Igrejas da Quarta Colônia. In: COLÓQUIO BRASILEIRO DE HISTÓRIA DA ARTE, 22, 2002. Anais... Porto Alegre: CBHA, 2002. Disponível em:<http://www.cbha.art.br/coloquios/2002/textos/texto09.pdf>. Acesso em 23 mar. 2018.

MOREIRA, Altamir. Aldo Locatelli e a Morte de São Luiz Gonzaga: sobrevivência das formas e expressão de sentimentos na pintura mural religiosa da Catedral de Novo Hamburgo. In: COLÓQUIO DO CBHA, 24, 2004, Belo Horizonte. Anais... Porto Alegre: CBHA, 2004. Disponível em: <http://www.cbha.art.br/coloquios/2004/textos/06_altamir_moreira.pdf>.

MOREIRA, Altamir. Angelo Lazzarini e a pintura mural religiosa nas igrejas da Quarta Colônia. In: BULHÕES, Maria Amélia. Memória em caleidoscópio: artes visuais no Rio Grande do Sul. Porto Alegre: UFRGS, 2005, p. 27 - 45. 
MOREIRA, Altamir. A morte e o além: iconografia da pintura mural religiosa da região central do Rio Grande do Sul (século XX). 2006. Tese (Doutorado) - Universidade Federal do Rio Grande do Sul, Porto Alegre, 2006.

MOREIRA, Altamir. Didi-Huberman: Reflexões sobre a síntese e o sintoma na teoria da arte. In: XXX Colóquio do Comitê Brasileiro de História da Arte. Rio de Janeiro: CBHA, 2010. Disponível em: <http://www.cbha.art.br/pdfs/ cbha_2010_moreira_altamir_res.pdf>

PANOFSKY, Erwin. Estudos de iconologia: temas humanísticos na arte do renascimento. Lisboa: Estampa, 1995.

PANOFSKY, Erwin. Significado nas artes visuais. São Paulo: Perspectiva, 2017.

RÉAU, Louis. Iconografía del arte cristiano: introducción general. Madrid: Del Serbal, 2000.

RIPA, Cesare. Della novissima iconologia del Cavalier Cesare Ripa Pervgino. Veneza: Cristoforo Tomafini, 1645. Arquivo PDF. Disponível em: < https://archive.org/details/iconologia00ripa>. Acesso em: 23 mar. 2018.

TREVISAN, Armindo. O rosto de Cristo: a formação do imaginário e da arte cristã. Porto Alegre: AGE, 2003.

TREVISAN, Armindo. A escultura dos Sete Povos. Porto Alegre: Movimento, 1978.

WEB ART GALLERY. Rosso Fiorentino. Esponsais da Virgem, $1523.325 \times 250 \mathrm{~cm}$. Óleo sobre madeira. Basílica de São Lorenço, Florença. Créditos da Imagem: Web Gallery of Art: Disponível em: <https://commons.wikimedia.org/w/ index.php?curid=7767054>. Acesso em: 24 mar. 2018.

WITECK, Ana Paula. A Vanitas em obras de arte contemporânea: um estudo iconográfico. 2012. Dissertação ( Mestrado em Artes)-Universidade Federal de Santa Maria, Santa Maria, 2012a.

WITECK, Ana Paula. Vanitas na arte contemporânea: um estudo iconográfico de obras de Nigel Cooke e Luis Zerbini. In: Anais do XI Seminário de história da Arte da UFPEL, 2012b. ISSN: 2237-1923. Disponível em: <https:// periodicos.ufpel.edu.br/ojs2/index.php/Arte/article/view/1709/1588>.

WITECK, Ana Paula. Exposições de arte contemporânea dedicadas à Vanitas: um retorno do gênero? In: Anais do V Ciclo de Investigações do PPGAV - UDESC. Florianópolis: UDESC, 2011. ISSN:1982-1875. Disponível em: < http:// docplayer.com.br/41650506-Exposicoes-de-arte-contemporanea-dedicadas-a-vanitas-um-retorno-do-genero.html >. 